\title{
Katma Değer ve Kalkınma Bağlamında Ürün Tasarımı
}

\author{
Doç. Dr. Serkan GÜNEŞ \\ Doç. Dr. Abdullah TOGAY \\ Çiğdem GÜNES \\ Öz
}

Kalkınma için yenilikle yüksek katma değerli ürün üretme zorunluluğu gündemi meşgul etmektedir. Ancak katma değerli ürünün ne anlama geldiği kadar, yenilik, katma değer ve kalkınma arasındaki ilişkinin açıklanmasında eksikler vardır. Günümüzde birçok işletme yoğun pazar rekabeti içinde yenilik baskısı yaşamakta, belirsizlik ve işlem maliyetleri yüzünden yenilik faaliyetlerini rutine dönüştürme konusunda kararsız kalmaktadır. Makalede tasarımın kalkınma için katma değer yaratma potansiyeli tartışılacak, tasarım özellikle işlem maliyetleri açısından teknoloji yoğun Ar-Ge faaliyetlerine alternatif işletme faaliyeti olarak önerilecektir.

Anahtar Kelimeler: Endüstriyel Tasarım, Ar-Ge, Teknoloji, Kalkınma, Katma Değer

\section{PRODUCT DESIGN IN THE CONTEXT OF VALUE ADDED AND DEVELOPMENT}

\begin{abstract}
Producing high value-added products through innovation has been engaged in the development agenda. However, there is still a lack of explanation about value-added products and correlation between innovation and development. Today although many business enterprises feel the pressure of innovation due to intense competition, many of them remain undecided in conversion of innovations to routines due to uncertainty and transaction costs. The article will discuss the potential of design in creating added value added for development and will propose design as an alternative business practice to technology intensive $R \& D$ activities especially in terms of transaction costs.
\end{abstract}

Keywords: Industrial Design, R\&D, Technology, Development, Value Added

Doç. Dr. Serkan GÜNEŞ, Gazi Üniversitesi, Mimarlık Fakültesi, Endüstri Ürünleri Tasarımı Bölümü, Ankara. E-Posta: serkangunes@gazi.edu.tr

Doç. Dr. Abdullah Togay, Gazi Üniversitesi, Mimarlık Fakültesi, Endüstri Ürünleri Tasarımı Bölümü, Ankara. E-Posta: atogay@gmail.com

Çiğdem Güneş, TUSAŞ-Türk Havacılık ve Uzay Sanayii A.Ş., Ankara.

E-Posta: cigdem.gunes@tai.com.tr 


\section{Giriş}

Endüstriyel tasarım faaliyetlerinin üründe, yüksek katma değer yarattığı, yaratılan katma değerin kapanması gereken cari açık ve kalkınma için önemli bir araç olduğu konusunda birçok söylem bulunmaktadır. Söylemlerin büyük bölümünde ifade edilen katma değer, kimi zaman kârı, bazen fiyatı, bazense gerçek anlamını ifade etse de, genel manada tasarım ürününün oluşturduğu iddia olunan yüksek katma değerden ne kastedildiği berrak değildir. Söylemler üzerinde yürütülecek tartışmalarda aynı ifade ile aynı şeyi kastetmek, anlamak için olmazsa olmaz koşuldur. Benzer bir çelişki, katma değer ve cari açık arasında görülmekte, her yaratılan ancak bileşiği belli olmayan katma değerin cari açığı kapatmada etkin bir unsur olarak görülmesi gerektiği savunulmaktadır. Diğer taraftan büyüme, gelişme, kalkınma ifadeleri birbirleri ile karıştırılmakta, kimi zaman birbirlerinin yerine kimi zaman ise tamamen farklı anlamlarda kullanılmaktadır. Hâlihazırdaki bu durumun temel sebeplerinden birisi öncelikle kullanılan terimlerin tanımının yapılmaması ve kastedilen anlam açısından fikir birliği olmamasıdır. Belki de en önemli sebep ise, tasarım etkinliği ve kalkınma arasındaki pozitif ilişkinin koşulsuz kabulüdür. Söylemin ötesine geçemeyen, detaylı ifadeler bütünü oluşturmadan yüzeysel şekilde ele alınan ilişki, çoğu zaman ampirik bilgiye dayanmadan savunulmakta, tasarım ile kalkınma gibi geniş bir kavramın bütünleştirilmesi aralarında bulunan farklar görmezden gelinerek yapılmaktadır.

Bu noktadan hareketle, makalenin ilk amacı tasarım ile kalkınma kavramı arasındaki ilişkiyi, tasarım ve teknoloji, teknoloji ve iktisadi büyüme ve iktisadi büyüme ve kalkınma ilişkisi olarak kademeli okumaktır. Kalkınma kavramından ekonomik büyüme kavramına doğru aşağı yönlü daha sonra ise ürün tasarımı kavramından teknolojik gelişme kavramına doğru yukarı yönlü bir okuma yapmak gerekmekte ve çalışma kapsamında önerilmektedir (Şekil 1). Böyle bir okumanın gerekçesi şu şekilde açıklanabilir. Her şeyden önce kalkınma içinde farklı yapısal dönüşümleri barındıran bir paradigma yani kapsamlı bir değerler dizisidir. Tasarım ise bir faaliyettir. Bir faaliyeti, kapsamlı bir paradigma ile karşılaştırmak ölçek problemi oluşturmaktadır. $\mathrm{Bu}$ nedenle iki unsur arasında karşılaştırma yerine ilişkilerine bakmak daha sağlıklı olacaktır. Ilişkileri bulmak için ise faaliyet ile paradigmayı bir kavram düzeyinde buluşturmak gerekecektir. Bu kavram ise teknolojidir. Zira kalkınma ekonomik büyümeyi de kapsayan bir olgu iken, ürün tasarımı teknolojik gelişmenin alt bileşenlerindendir. $O$ halde evvela teknolojik gelişme ile iktisadi büyüme arasındaki ilişkinin teorik altyapısının ele alınması gerekmektedir. Böylelikle; öncelikle kavramlar arasında ilişkilendirmeyi zorlaştıran farklar ifade edilecek daha sonra ise ilişki ağı her aşamada silsile 
halinde tekrardan kurgulanmaya çalışılacaktır.

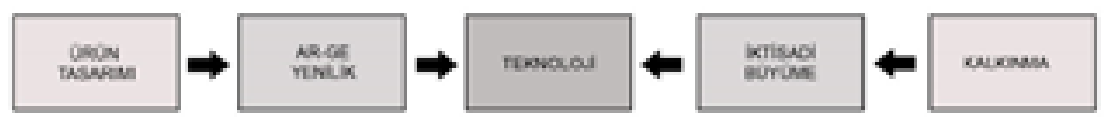

Şekil I: Ürün tasarımı ile kalkınma ilişkisi

Makalenin ikinci amacı ise sıklıkla karıştırılan katma değer ve kalkınma kavramlarının açıklamalarını yapmaktır. Bu açıklama daha ziyade sadeleştirilmiş olarak yapılacak, aşırı detaydan kaçınılacaktır. Gerek katma değer gerekse de kalkınma kavramı başlı başına bir alan olmaları nedeniyle izahat kavram alanlarında yer alan ana eksenler, benzerlikler ve karşıtıklar üzerinde yoğunlaştırılmıştır.

\section{Değer, Katma Değer Ve Katma Değerli Faaliyet Nedir?}

Bir mala verilen öneme veya kıymete değer denir. Değer, iktisadın tartışmalı konularından birisi olup, malın sağladığı fayda kadar malın bol veya kıt olması ve malın kalitesiyle ilişkilidir. Klasik iktisatçılar bir mal ve hizmetin değerini harcanan emekte aramış, Ricardo'nun mübadele değerini gündeme taşımasıyla fayda kavramı gündeme gelmiştir. Konu fayda olduğunda tartışma derinleşmiş, özellikle Jevons, Menger ve Walras gibi Neo-Klasik iktisatçılar değeri "marjinal fayda" üzerinden piyasadaki değişim sürecinde aramışlardır. Tartışmalar devam etse de değer, üretim maliyetleri ile söz konusu şeyin sağladığı faydanın bir fonksiyonu olarak görülmektedir. Değer konusunda büyük yanılgılardan birisi, değerle fiyatın eş görülmesidir. Gerçekte fiyat ve değer farklılaşabilmekte, fiyat dışsal faktörlerin etkisiyle gerçek değerin altında veya üstünde oluşabilmektedir. Katma değer ise bir ürünün satış fiyatından, o ürünü ortaya çıkarmak için başkalarından satın alınan şeylerin düşürülmesinden sonra ortaya çıkan bakiyedir (de Chernatony ve diğ., 2000). Bu miktar içerisinde kar, kira, ücretler ve faiz bulunur. Yani katma değer, çıtı ile girdi arasındaki farka işareteder (Brandenburgerve Stuart, 1996). Milli hasıla ise bir memleketteki bütün ekonomi birimlerinin mal ve hizmet üretiminde yarattıkları katma değerler toplamıdır (Daly, 1996). Katma değer ile milli hasıla arasında doğrudan ilişki bulunmakta, yüksek katma değer yüksek hasıla anlamına gelmektedir. İşletmelerde amaç dâhilinde tekrarlı işlemlere faaliyet denir. Faaliyetleri katma değer yaratan veya yaratmayan olarak sınıflamak mümkündür. Katma değerli faaliyetler sunulan malın değerini arttırır. Basit bir ifade ile eğer bir faaliyet ürüne değer katıyorsa katma değerlidir ve daha da ötesi faaliyet mukayese açısından diğerlerine oranla fazla katma değer 
yaratıyorsa bu faaliyet daha yüksek katma değerlidir (Davis ve Kay, 1990). İşte yüksek katma değerli ürün, içeriğinde mukayese edilen ürüne karşı yüksek katma değerli faaliyetleri barındıran, müşteriye daha fazla fayda sağlayan dolayısıyla milli hasılayı daha fazla artıran üründür.

Günümüzde yüksek katma değerli ürünler ve cari açık arasında ilişki kurulduğu görülmekte, yüksek katma değerliürünlerin cariaçığı kapatmakta etkin bir araç olduğu savunulmaktadır. Bu tartışmalarda ifade açısından yapılan en büyük hata cari açık kavramı ile dış ticaret açı̆̆ının karıştııımış olmasıdır. Zira cari açık, iktisadi birimler sahip oldukları kaynakların ötesinde harcamaya başlarlarsa ortaya çıkar ve elbette ihracat-ithalat arasındaki farkı tanımlayan mal dengesini de kapsar. Dolayısı ile dış ticaret açığı denildiğinde cari açığın yalnızca bir alt bölümü olan mal dengesi anlaşılmalıdır. Cari açık ise dış ticaret dengesi ile hizmetler, yatırım gelirleri dengesi ve cari transferler dengesini de kapsar. Bu nedenle yüksek katma değerli ürünlerin üretilmesi, sadece dış ticaret açığına tesir etmekte, ancak kendi başına tüm cari açığı kapatma kudreti bulunmamaktadır. Tartışmalarda eksik olan bir husussa, katma değer içindeki milli katma değerin tanımlanmamasıdır. Zira bir ürünün yüksek katma değer yaratması, her zaman ürünün dış ticaret açığını kapatmakta etkili olacağı anlamına gelmez. Asıl önemli olan yaratılan katma değer içindeki milli katma değerdir. Söylemlerde daha ziyade yüksek katma değerli ürünler olarak ileri teknoloji ürünler öne çıkarılmakta ancak ürünlerin milli katma değer oranı göz ardı edilmektedir. Velev ki elimizde cep telefonu ve pamuk gibi iki ürün bulunsun. Dış ticaret açığı açısından önemli olan, bu ürünlerden hangisinin ihracatının daha fazla milli gelir yaratmış olduğudur. Bu iki ürünün satış fiyatları içinde hangisinde diğerine oranla daha fazla milli katma değer varsa o ürünün ihracatı milli geliri daha fazla arttırır. Yani bir telefonu üretmek ve yurtdışı pazarlara satmak kadar telefonu üretirken daha az ithal malzeme kullanılması dış ticaret dengesi açısından mühimdir.

Bu kısma kadar ifade edilenleri özetlemek gerekirse şu çıkarımları yapmak mümkündür. Katma değer ürünün fiyatı değil ürünü ortaya çıkarmak için başkalarından satın alınan unsurların düşürülmesinden sonra ortaya çıkan bakiyedir. Bu nedenle bir üründe yüksek katma değer açısından esas olan, hammadde tedarikinden üretimine ve müşterinin eline geçene kadar ürün faydasınıarttırmakkadarmillikatma değermiktarınıdaarttırmaktır. Böylelikle dış ticaret açığını kapatmada ihtiyaç duyulan, salt yüksek katma değerli ileri teknoloji ürünleri veya tasarım ürünleri değil, milli katma değer miktarı yüksek ileri teknoloji veya tasarım ürünleridir. Böyle bir sav gerekçesini hem karşılaş̧ırmalı üstünlük teorisinden hem de değer teorisinden almaktadır. Bir malın milli olması, o malın değer zincirinde milli girdinin fazlalığına işaret 
eder. Değer zincirinde milli miktarı ne kadar yüksek ise üretilecek katma değer daha fazla ülke içinde yaratılmış anlamına gelmektedir. Bu nedenle herhangi bir ürünün milli katma değer oranı, katkının o ürünün üretiminin ilk aşamalarına doğru ilerlemesiyle artmaktadır. O yüzden montaj sanayi gibi pratiklerin milli katma değer oranı düşüktür.

\section{Büyüme ve Kalkınma Nedir?}

Tasarım kavramı ve kalkınma arasındaki ilişkinin tanımlanması konusunda yapılan yanlışlardan birisi büyüme, gelişme ve kalkınma ifadelerinin eş anlamlı olarak kullanılmasıdır. Bu nedenle öncelikle bahsi geçen ifadelerin neyi içerdiği ve birbirleri ile ilişkilerinin tanımlanması önemlidir. Zira tasarım kavramı doğrudan kalkınma kavramı ile ilişkilendirilmekte, bu durumda iki kavramın arasındaki ölçek farkları nedeniyle birbirini tamamen karşılayan bir karşılaştırma veya eşleştirme yapılamamaktadır. Burada ölçek farkından kasıt, kalkınmanın çok büyük bir yapısal değişimine işaret ederken, tasarım bu yapısal değişimdeki herhangi faaliyetten birisidir. Bu yaklaşım tasarımın önemini inkâr etmemektedir. Söylenmek istenen tasarımın ancak kalkınma için kullanılabilecek alt faaliyetlerden biri olabileceğidir. Zira tasarımın tek başına kalkınmayı sırtlanabilecek kudrette olmaması her iki kavramı bağımlı ancak karşılaştırması zor iki unsur haline getirmektedir.

İktisadi büyüme (büyüme), genel anlamda herhangi bir ekonomide zaman içindemal vehizmetüretimi miktarında artışileiktisadifaaliyetlerin ölçeğinde meydana gelen büyümeyi ve kişi başına düşen hasılanın büyümesini ifade eder (Sullivan ve Sheffrin, 2003: 310). Kalkınma (kimi zaman gelişme) ise, salt üretimin ve kişi başına gelirin arttırılması değildir, az gelişmiş bir toplumda iktisadi ve sosyo-kültürel yapının değişmesi ve yenileştirilmesidir (Han ve Kaya, 2012: 2). Kalkınma, az gelişmişlikle ilgili iken geniş anlamda büyümeyi de içermektedir. Ancak büyüme olmadan kalkınma olamayacağı gibi her büyüme kalkınma demek değildir. Flammang'a göre büyüme aynı olandaki artışı, ekonomik kalkınmaysa yapısal değişme sürecini ifade eder (1979: 50). Bu kavramlar arasındaki ilişki kısa dönemde rekabet halinde, uzun vadede ise birbirini tamamlayıcı niteliktedir (Flammang, 1979: 61). Salt iktisadi büyüme ile temelini beşeri sermayeden alan kalkınmayı yakalamak mümkün gözükmemektedir.

\section{Teknoloji ve Kalkınma İlişkisi}

Teknoloji, bir mal veya hizmetin üretimi için gerekli ve uygulanan bilgi ve deneyimdir. Teknolojinin iktisadi olarak ele alınş̧ biçimi farklı yaklaşımların çıkmasına sebep olmuştur. Neo-Klasik üretim fonksiyonu yaklaşımında teknoloji başta dışsal ve kamu malı olarak kabul edilmiştir. Teknoloji ile 
büyüme ilişkisi ampirik olarak Solow tarafından ele alınmış, teknolojik ilerlemeyi (işgücünün eğitimini de kapsar. s:312) büyümenin, bir bakıma kişi başına gelirdeki artışı sağlayan en önemli girdisi olarak tanımlamıştır (1957). Solow bu çıkarımını Toplam Verimlilik Faktörü (TVF) ölçümlerine dayandırmış, geleneksel modellerde büyümeye neden olarak gösterilen emekçi ve sermaye faktörleri dışında ileride Solow Artığı (Residual) olarak anılacak olan teknoloji artığına ulaşmıştır. Ancak Solow'un modelinde teknolojinin kaynağı meçhul kabul edilmiş ve dışsal bir değişken olarak görülmüştür. Teknoloji bir şekilde, bir yerlerde ortaya çıkmakta sonra ekonomiye girip, TVF'de artışına neden olmaktadırlar. Daha sonraları dışsallık yaklaşımı büyük eleştiriler alsa da, modelin en büyük katkısı teknolojinin (teknik değişimin) büyüme değişkeni olarak gündeme getirmesidir.

Romer, büyümenin asli unsuru olarak teknolojik gelişmeyi görmüştür (1990). Ancak ona göre teknolojik gelişme dişsal değil; onun yerine firmaların bilinçli kararları sonucu ortaya çıkan içsel bir üretim faktörüdür (Romer, 1990: 72). Neo-Klasik büyüme yaklaşımından ayrı olarak kaynağı tanımlanmayan teknolojik gelişme işletmelerin kar ya da fayda fonksiyonunu yükseltmek için içsel olarak ürettikleri faaliyetler olarak tanımlanmıştır. Modelde teknolojik gelişmenin üretim maliyeti ilk sabit maliyetine eşit görülmüştür. Böylelikle teknolojik gelişme diğer mallardan farklı bir özelliğe bürünmüştür. Endojen (içsel) büyüme modeli denilen bu modelde büyüme, teknik bilgiye dayansa da bedelsiz olan teknoloji, maliyetleri düşürürken kaliteyi yükseltmektedir. Teknolojinin kamusal niteliği değişmemekte, teknoloji yatırımları neticesinde işletmeden taşarak sektörün geneline yayılmaktadır. Modelde, artan verimlere dayalı üretim fonksiyonu kullanılmakta, kararlar ve faaliyetler sonucu ortaya çıkan bilgi ekonominin genelinde verimlilik artışı sağlamaktadır. Endojen büyüme modellerine bir katkıda Lucas'tan gelmiştir. Lucas beşeri sermayeyi üretim faktörü olarak tanımlamıştır (1988). Lucas'a göre bu sermaye, eğitim ve yaparak öğrenme vasıtasıyla oluşabilmektedir.

Evrimci iktisat olarak adlandırılacak Schumpeter'ci yaklaşımda ise (1943) Neo-Klasik yaklaşımın görmezden geldiği büyüme ve kalkınma arasındaki ilişki üretim faktörleri üzerinden kurgulanmıştır. Genel anlamda üretim faktörleri, ürün için lazım olan tüm unsurlardır. Schumpeter'ci yaklaşımda sermaye, emek ve toprak üretim faktörlerine gayri maddi unsurlar olarak teknoloji (yenilik) ve sosyo-ekonomik unsurlar (girişimcilik) eklenmiş, son iki unsur Schumpeter tarafından kalkınmanın asli unsurları olarak görülmüştür. Schumpeterci yaklaşım kalkınmayı doğrusal bir hareket olarak görmemiş, zaman içinde kesintiye uğrayan ve dengesi bozulan ancak yine 
ardışık yenilikler ve girişimci teşebbüsleri vasıtasıyla tekrar geçici dengeye ulaşan bir devingen süreç olarak tanımlamıştır. Yaklaşımda teknoloji dışsal değil içseldir. İşletmeler asli amaçları için teknoloji üretmekte ve teknoloji öncelikli rekabet aracı olmaktadır. Schumpeter yaklaşımında teknoloji daha ziyade buluşlar ile özdeşleştirilmekte, pratikteki büyük yoğunluğu oluşturan artımsal teknolojik gelişmeler göz ardı edilmektedir. Bu nedenle süreç zaman içinde kesintiye uğramaktadır.

İçsel teknoloji yaklaşımı Nelson ve Winter tarafından da ele alınmış, ekonomik kalkınma için teknolojik değişim talep faktörleri çerçevesinde ifade edilmiştir. Modelde yenilikçi işletmeler heterojenliğin sağladığı rekabet için yeni rutinler (bilgi kodları) geliştirmekte, takipçiler rant için başarılı rutinleri kopyalayarak transfer etmektedir (Nelson ve Winter, 1982). Bilgi asimetrik olduğundan işletmeler rekabet halindedir ve teknoloji kolayca ulaşılabilen bir faktör olmaktan çıkmıştır. Teknoloji, üretilmesi için çaba ve kurumsal altyapı gerektiren ve rekabetçi üstünlükler kazandıran bir faktöre dönüşmüştür.

Yukarıdaki ifadeler doğrultusunda teknoloji ve kalkınma arasındaki ilişki için şu çıkarımları yapmak mümkündür. Neo-klasik okul, teknolojiyi bir müddet görmezden gelse de, gerek okulun kendi içindeki dönüşümü gerekse evrimci iktisat söylemlerinin ortaya çıkması ile teknoloji gayri maddi üretim fonksiyonu olarak rekabetçi ekonominin, iktisadi kalkınmanın tamamlayıcı bir parçası haline gelmiş̧ir. Teknoloji, iktisadi büyüme için düşük maliyetli ve yüksek kaliteli ürünler (yani verimlilik sağlayabildiği) kadar, yeni seçenekler sunan ürünlerinde ortaya çıkmasını sağlamaktadır. Teknolojinin etkin hale gelmesi, rekabetçi piyasalarda yeni teknoloji üretmek veya teknolojiyi transfer etme sorunlarını çıkarmış ve ülkeler arası gelişmişlik yarışının en belirleyici unsuru haline gelmiştir.

\section{Tasarım ve Katma Değer îlişkisi}

Katma değer, bir işletmenin dışarıdan tedarik ettiği girdilere kendi bünyesinden kattıklarıdır. Bu sebepten katma değere ulaşmak için girdi maliyetlerinin cirodan çıkarılması gerekmekte, işletmenin ödediği ücretlere ve işletme karına ulaşmak mümkün olmaktadır. Yinelemek gerekirse katma değer salt işletme karından oluşmaz ve işletmenin ürettiği ürün fiyatı ile dışarıdan sağlanan hizmetlerin birim maliyeti arasındaki farktır. Katma değeri arttırmak için ya işletme karının ya da katma değere esas olan işçilik içeriğinin arttırılması gerekir. İhtiyaç olan, ya ürün fiyatını yükseltmek ya da fiyat sabitken girdileri düşürmektir. Rekabetçi piyasalarda ürün fiyatlarını gerekçesiz yükseltmenin bir gerçekliği bulunmadığından yapılması gereken girdi maliyetlerini düşürmek için teknolojik gelişme ya 
da ürün fiyatını arttıracak markalaşma çalışmalarıdır. Elbette teknolojik gelişme (teknoloji geliştirme veya transferi) ve markalaşmanın cari giderler yaratacağından önemli olan cari girdilerle ürün fiyatı arasındaki pozitif fiyat farkıdır. Katma değer artırmak için yapılacak yatırımların birim üründe cari girdileri (maliyetleri) birim ürünün fiyat artışının altındaysa, yani yapılan yatırımla yeni fiyat arasında pozitif fark varsa katma değer yaratılmaktadır. Yinelemek gerekirse, daha yüksek katma değer daha yüksek karlılık anlamına gelmemektedir. Kar sabit veya düşerken işçilik ücreti artışı yakalanabilir.

Katma değer artışının bir boyutuysa ürünün daha çok bilgiyle işlenmesidir. Katma değer artışı için tasarım, Ar-Ge, yenilik ve markalaşmaya ilgi gösterilmesi yazında ve söylemlerde sıklıkla ele alınmaktadır (Griliches, 1995, Greenhalgh ve Longland, 2006: 309). Bu yaklaşımın arkasındaki gerekçe, emek yoğun ürünlerden bilgi yoğun ürünlere geçilmesi, bir bakıma işçiliğin niteliğinin değişmesidir. Böylelikle, ya fiyat sabitken daha yüksek işçilik içeriği sağlanabileceği (Griliches, 1995) ya da aynı zamanda ve mümkünse verimli Ar-Ge sayesinde daha yüksek niteliğe ve fiyata sahip ürünlere, kısaca karlılığa ulaşılabileceği öngörülmektedir (Grossman and Helpman, 1991).

Bu aşamada öncelikle şu sorunun sorulması gerekmektedir. Tasarım katma değer yaratan bir faaliyet midir? Daha önce bu çalışmada katma değerli faaliyetleri müşteriye fayda sağlayan faaliyetler olarak tanımlamıştır. Eğer tasarım müşteriye bir değer sağlıyor ise (ki sağlar) ön kabul olarak katma değerli bir faaliyettir. O halde iletmelerin katma değerli bir faaliyet olan tasarıma yatırım yapıp yapmayacakları cevaplanması gereken bir sorudur. Buna cevap verebilmek için izlenecek ilk yol yatırım maliyetleri üzerinden yapılacak bir analizdir. Eğer işletmelerin birim ürün bazında tasarım için yapacakları fazladan maliyet miktarı (Maliyet $B>$ Maliyet $A$ ) ile sağlanan fiyat avantajı arasında pozitif bir fark (Katma Değer $B>$ Katma Değer A) oluşuyorsa(ki bunun garantisi yoktur) bu alana yatırım yapmak mantıklıdır (Şekil 2).

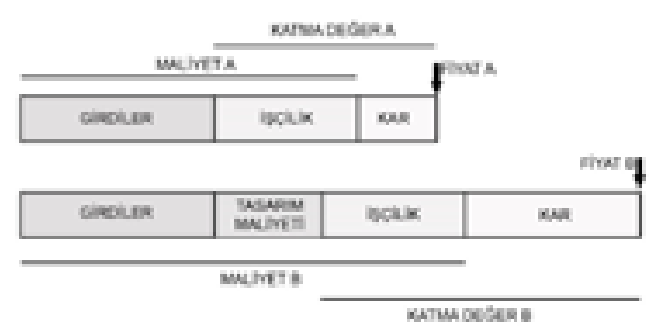

Şekil 2: Tasarım yatırım koşulu 
Şekilde işletme girdileri ve işçilik sabit iken Koşul 2' de firma tasarıma yatırım yaparak maliyetlerini arttırmıştır. İşletme yeni ürünü Fiyat B'den satarak daha yüksek kar elde etmiştir. İşletmenin yeni karı tasarım maliyetleri ve eski karının toplamından yüksekse (Kar B > [Tasarım Maliyeti + Kar A]) işletme daha fazla katma değer yaratmış olacaktır. Faaliyetleri arasına tasarımı ekleyen işletmelerin yüksek katma değer sağlamasının bir nedeni de işçilik içeriklerinin değişmesidir. Tasarım bilgi yoğun faaliyet olduğundan işçilik içeriği emek yoğundan bilgi yoğuna doğru ilerlemektedir. Tasarım maliyetleri eklenen koşulda ürün fiyatı neden artar? Artışın ilk sebebi tasarım yatırımının maliyetidir. Ancak daha da önemlisi kardaki artıştır. Kardaki artışa imkân veren ise ürün farklılaştırılması nedeniyle işletmeye fiyatı arttırmasına olanak sağlayan tekelci kar; geçici ranttır. Bu rantı sağlayan kapitalist teşebbüs iradesi ve zekası tarafından yaratılan, statikliği bozan yenidir (Schumpeter, 1943). Tasarım yeni ürüne sebep olmakta, işletmelerin emsallerinden daha yüksek fiyat talebine olanak vermektedir.

\section{Ar-Ge mi, Tasarım mı?}

Tasarım ve Ar-Ge faaliyetlerinin yüksek katma değerli ürünlere sebebiyet verdiği halde işletmelerin bu faaliyetleri bünyelerine katmamalarındaki sebepler nelerdir? Bu soruya cevap vermeden önce işletmelerin varlık sebebinin öncelikle karlılık ve büyüme daha sonra işlem maliyetlerini düşürmek olduğunu hatırlatmakta fayda vardır. Hal böyle iken daha önce bu faaliyetlerde bulunmayan işletmelerin bu tür rutinler için yüksek işlem maliyetleriyle karşılaşacağını söylemek yanlış olmaz. İşlem maliyeti kavramı Coase ile gündeme gelmiş, Coase işletmelerin neden bütün işlemlerin piyasalarda gerçekleştirilmediğini açıklamaya çalışmıştır (1937). Kavrama göre işletmeler işlemler serisi olarak görülmekte, firmalar bu işlemlerin firma bünyesinde yapılması veya piyasadan temini konusunda (Willamson, 1975)maliyetlerdeki farka göre karar vermektedir. Williamson (1975) işlem maliyetleri açısından faaliyetlerin işletme içinde yapılmasını piyasaya göre daha avantajlı ve daha etkin bir organizasyon olarak görmektedir. Bir faaliyetin işletme bünyesi içinde yapılması ve rutin olması kolay değildir. Bu nedenle işletmeler tasarım ve Ar-Ge gibi yüksek belirsizlik içeren konularda öncelikle var oldukları durumu koruma tutumu göstermekte ya da daha etkin konum için diğer işletme rutinlerini taklit etmektedir. Eski rutinlerin etkisini kaybettiği piyasalarda, başarılı rutinlerin taklidi makul olsa da, bu rutinlerin transfer maliyetleri ve örtük bilginin transferinde yaşanan güçlükler, yeni rutinin yaratılması seçeneğini doğurmaktadır.

Dolayısıyla Ar-Ge hizmetlerinin işletme içinde mi yürütüleceği yoksa piyasada sair işletmelerce yürütülen Ar-Ge çalışmalarının işletme bünyesine 
mi transfer edileceği işlem maliyetleri ile ilgili bir husus olduğu kadar aynı zamanda yerleşik işletme kültürü ve geçici işletme iklimi ile alakalıdır. Ar-Ge maliyetleri için yeterli risk sermayesine sahip olmayan işletmeler maliyet liderliği stratejisi yürütmekte veya teknoloji transferine (her türlü ticari anlaşmayı kapsayan ve know-how transferi) yönelmektedir. Yenilikçi olmak rasyonel işletme mantığı içinde maliyetler üzerinden yapılan bir tercihtir. Rekabetçi piyasa, işletmeleri Ar-Ge faaliyetlerine zorlarken, işletmeler maliyetler üzerinden tercihte bulunmaktadır.

Konu maliyet olduğunda tasarım veya Ar-Ge faaliyetleri konusunda tercihi iki husus belirler. IIlki piyasadaki hâkim rekabet şeklidir. Eğer piyasa Ar-Ge tabanlı bir rekabete sahipse salt tasarım faaliyetleriyle rekabetçi üstünlük sağlamak mümkün olamayacaktır. Piyasada tasarım rekabet için yeterliyse, maliyetler açısından öncelikle tasarıma yönelmek rasyonellik içinde mantıklı olacaktır. Zira tasarım faaliyetleri gerek maliyetler gerekse kısa proje erimleri açısından Ar-Ge faaliyetlerine oranla daha az risk sermayesi gerektirmektedir. Düşük seviyedeki sermaye birikimleri KOBi'lerin tasarım faaliyetlerine yönelmelerini ve rutin geliştirmelerini engellemektedir. Tasarımın Ar-Ge'den diğer farkı rutin transferinin kolaylığıdır. İşletmeler tasarım ihtiyaçlarını danışmanlıkla temin edebilmektedir. Nitekim eğer işletmenin yeterli risk sermayesi bulunmuyorsa ve piyasada tasarım faaliyetleri rekabetçi üstünlük sağlıyorsa, Ar-Ge yerine ilk olarak tasarım faaliyetlerine yönelmesi işlem maliyetleri açısından uygundur. İşletmelerin yeniliği bir üretim faktörü olarak bünyelerine katma amacıyla, tasarım faaliyetlerinin ilk olarak gündeme gelmesi, maliyet açısından korunaklı şekilde rutin geliştirmeye imkân verirken bu alanda olası piyasa başarıları işletmelerin yüksek maliyetli Ar-Ge faaliyetlerine yönelmesi konusunda cesaretlendirecektir.

\section{Tasarım ve Kalkınma İlişkisi}

Bir kavramın iktisadi boyutu yarattığı iş hacmi, sağladığı katma değer (GSMH), ürettiği istihdam ile ölçülür. 2015 tarihli Avrupa'da Endüstriyel Tasarımın Ekonomik Özeti isimli raporda (Europa Economics), Avrupa'da yer alan 470 sektörden 165'inin tasarım yoğun sektörler olduğu gözükmektedir. Bu sektörler 2013 yılında 1,6 trilyon Euro ile Euro bölgesi gayri safi hasılasının \%13'ünü üretmektedir (EPO \&OHM, 2013). Bu hasılanın 123 milyar Euro'su doğrudan endüstriyel tasarım faaliyetlerinden oluşmaktadır (Europa Economisc, 2015). Diğer taraftan 2008 yılında İngiltere'de tasarım faaliyetlerinin yıllık cirosu 33.5 milyar pound iken (Haskel ve Pesole, 2011), 2007 yılında Danimarka'da 3,5 milyar Danimarka kronu (The Danish Goverment, 2007), İrlanda'da 2010 
yılında 498 milyon Euro'dur (Indecon, 2010). Yine İngiltere'de yapılan bir çalışmada tasarıma yapılan her 100 euroluk yatıımın 225 euro geri dönüş sağladığı raporlanmıştır (Kang, 2015). Ekonomik büyüme için etkin bir araç olan tasarımın, ekonomik bir aktör olan firmaların karlılığına (Candi ve Saemundsson, 2011), nakit akışına (Hertenstein ve diğerleri, 2005) ve genel olarak ekonomik performansına (Candi ve Gemser, 2010) katkı sağladığı belirlenmiştir. İktisadi büyümeye sebep olacak sürükleyiciler arasında yer alan yeni ürün geliştirme faaliyetleri (Dahlstrand ve Stevenson, 2010) bu özelliğini özellikle doğrudan sağladığı katma değer ile almaktadır. İktisadi büyüme ise kalkınmanın ihtiyaç duyduğu kaynağı sağlamaktadır.

Günümüz iktisadi yaklaşımlarında, verimliliğin istihdam artışı sağladığı, teknolojik gelişmenin verimliliğe katkı sağladığı konusunda oydaşma bulunmaktadır. Bu yüzden teknolojinin gelişmesi ve yüksek katma değerli yeni ürünlerin yaratılması rekabetçi ekonomi için tamamlayıc kalkınma için belirleyicidir. Talep tabanlı pazarlarda ürünü ucuz üretmek değil yeni tekniklere ve performansa haiz (Porter, 1990) tüketici ihtiyaçlarına ve özelliklerine uygun ürünleri pazara sunmak önemlidir. Girişimciye kâr getiren ve teknolojik gelişmeler sonucu ortaya çıkan ve ticari bir ürüne dönüşen her şey yenilik (inovasyon) ise tasarım yeniliğin hem parçası hem biçime bürünmüş halidir. Zira tasarım kaynağını yeni, farklı fikirlerden alır, fikirleri tüketici faydasına çevirir. Nitelikli tasarım üründe işlev veya estetik anlamda veya her ikisi açısından katma değer yaratır. Düşünce aşamasında kalan, vücut bulamayan fikir tüketici ile buluşmadığı yani inovasyona dönüşmediği sürece müddetçe katma değere konu değildir.

Tasarımın yeniliğin ayrılmaz ve tamamlayıcı parçası olması (Mutlu ve Er, 2003) onu her katma değer sağlayan faaliyet gibi büyümenin ve kalkınmanın temel araçlarından yapmaktadır. Hızlı olması gelişmekte olan ekonomilerde tasarımın belirli altyapıya zorunluluğu aşikârdır.

- Geç sanayileşen toplumlarda tasarım faaliyetleri yoğun değildir. Sanayileşme için teknoloji yoğun mühendislik Ar-Ge'ye önem verilmekte, yenilik kültürü oluşturmada öncü ve düşük maliyetli tasarım faaliyetlerinin önemi indirgenmektedir.

- Üretimde maliyet liderliği ve ölçek öne çıkarılmakta, tasarım faaliyetleri belirsizlik kaygısıyla görmezden gelinmektedir.

- İşletmeler markalaşma ve tasarım faaliyetleri amacı ile kurulmamakta, bu tür faaliyetler ancak rekabetçi piyasa zorlamasıyla gündeme gelmektedir. 
-Düşükrisksermayesiişletmeleritasarımfaaliyetlerindenuzaklaştırmakta, işletmeler teşvik sistemine bel bağlamaktadır.

- Fikrive sınai haklar konusundaki eksiklikleryenilikçiliğicezalandırmakta, geçici ranta kısa sürede diğer işletmeler ortak olmaktadır.

- Tasarım salt estetik fayda düzeyine indirgenmekte ve Ar-GE'nin son aşamalarında sürece girmektedir.

Kalkınma, refahı arttırmaya yönelik iktisadi potansiyelin harekete geçirilmesidir. Geri kalmış ekonomilerin çıkmazı beşeri ve maddi sermayenin kıt oluşu ve kaynakları kullanıma sokmada eksikliktir. Bu nedenle kıt sermayenin etkin şekilde kullanılması kalkınma politikalarının temelini oluşturmuştur. Doğrusal kalkınma modeli reçetelerinde (Hozelitz, 1990; Rostow, 1960; Kuznetz, 1955; Fisher, 1939) maddi üretim fonksiyonlarına dayalı ilksel üretim faaliyetlerinden gayri maddi üretim fonksiyonlarına dönük bir yaklaşımı önerilmektedir. Dolayısıyla az gelişmişlik ve gelişmişlik arasındaki farkta, yenilik üretebilme ve girişimcilik belirleyicidir (Wallerstein, 1974). Kıt kaynaklarla yenilik üretmek ancak yenilik potansiyeli yüksek sürükleyici alanlara yatırımla mümkündür. Zira Ar-Ge ve tasarım alanlarında fazla kapasite ve değer yaratmak, iki noktadan önemlidir. İlki iş̧̧ilik içeriğinin emek yoğundan bilgi yoğuna doğru yönelmesidir ki, birim istihdamla üretilecek katma değer artacaktır. İkincisi yeni olanı yaratmadır ki, işletmeler kısıtlı maliyet liderliği yarışından kurtularak yeni olmanın sağladığı geçici ranttan faydalanacaktır.

Tasarım kavramı Ar-Ge kavramının içinde yer alsa da, uygun koşullarda, ihtiyaç duyduğu daha düşük risk sermayesi, düşük işlem maliyeti ve kısa proje erimleri nedeniyle Ar-Ge yerine kullanılabilecek bir araçtır. Tasarım, özellikle gelişmekte olan ülkeler açısından yaratacağı rekabetçi pozisyon nedeniyle gelişme için stratejik konumdadır (Er, 1997). Tasarım olası Ar-Ge faaliyetlerine işletme kültürü ve rutin geliştirme açısından altlık sağlama potansiyeline sahiptir (Güneş, 2011). Kıt sermayenin eşit dağılımı düşük ölçekli işletme tiplerini ortaya çıkartmakta, işletmeler Ar-Ge faaliyetleri yürütememektedir. Gelişmekte olan ülkeler için, başlangıçta tasarım temelli yüksek katma değeryaratma faaliyetleriöne çıkmakta zamanla uzmanlaşma daha yüksek katma değerli ürünlerin Ar-Ge tabanlı geliştirilmesine imkân vermektedir.

\section{Sonuç Yerine}

Bu çalışmada endüstriyel tasarım disiplininde sıklıkla alanın önemini ifade etmede kullanılan katma değer kavramı açıklanmaya çalışılmıştır. Böyle 
bir çabanın arkasındaki temel sebep katma değer kavramının, eğer dikkat edilme ise, ekonomi alanındaki diğer kavramlar ile karıştırılma ihtimalidir. Yinelemek gerekir ise, katma değerli ürün daimi suretle yüksek fiyatlı veya ileri teknolojili ürün değildir. Katma değerli ürün daha ziyade öz unsurlar ile ortaya konulan üründür. Bir işletme bir ürüne ne kadar kendinden değer veriyorsa, yani ürünün ortaya çıkması için gereken faaliyetlerde ne kadar etkili ise o ürün katma değerlidir. Bu noktada tasarım faaliyetinin firma tarafından yapılıp yapılmadığı veya dışarıdan özellikle ülke dışından hizmet alımı veya lisans yolu ile tedarik edildiği üzerinde durulması gereken ana hususlardandır. Bu yüzden, yüksek katma değer yaklaşımı açııından tasarım faaliyetlerinin firma içinde üretilmesi, milli katma değer açısından ise lisanslı üretim yerine özgün tasarımlara ağırlık verilmesi ve tasarım faaliyetlerinin milli imkânlar ile üretilmesi gerekmektedir.

Gelişmekte olan ülkelerin temel çıkmazı kısıtlı sermaye birikimidir. Sermayenin kıt olması risk sermayesinin oluşmamasına yol açmakta, düşük ölçekli işletmeler yüksek işlem maliyetleri nedeniyle maddi üretim faktörleri üzerinden rekabetiyürütmektedir. Rekabetinyenilikve girişimciliküzerinden yürümesiyle teknolojik gelişme kişi başındaki gelirde artışı sağlayan tek faktör haline gelmiştir. İşletmelerin kararlarını etkileyen en önemli unsur pazardaki rekabetin yapısı ve rekabet için geliştirecekleri rutinlerin işlem maliyetidir. Bu meyanda, Ar-Ge ve tasarım faaliyetlerinin gerekliliğini mevcut pazar yapısı belirlemekte, zorunluluk ortaya çıktığındaysa işletmeler girdi maliyetleri ve üretilecek katma değer üzerinden yatırım kararı vermektedir. Eğer yatırıma konu olan cari girdilerle fiyat arasındaki pozitif fark ihtimali bulunuyorsa, işletmeler Ar-Ge ve tasarım faaliyetlerini rutin olarak bünyelerinde üretmekte ya da transfer etmektedir.

Ar-Ge ve ürün geliştirme yeteneği ile yüksek katma değerli ürünler arasında pozitif bir ilişki bulunmakta, ülkeler için yüksek katma değerli ürün üretme yeteneği geliştirme, dış ticaret açığının kapatılmasında bir yaklaşım olarak ortaya çıkmaktadır. Ar-Ge faaliyetlerinin yüksek risk sermayesine ve kültüre ihtiyaç duyması, özellikle gelişmekte olan ülkeler için yüksek katma değer için alternatiflerin gündeme gelmesini zorunlu kılmıştır. Bu faaliyetler arasında ürün tasarımı, nitelikli Ar-Ge kadar yüksek katma değer vaat etmese de göreli olarak ihtiyaç duyduğu risk ve beşeri sermayenin düşüklüğü, kısa proje erimleri ve somut ürün çıktıları ile Ar-Ge faaliyetlerine alternatif olmaktadır. 


\section{Kaynakça}

Brandenburger, A. M., and Stuart, H. W. (1996). "Value-based business strategy.”Journal of Economics and Management Strategy, 5, 5-24.

Candi, M., and Gemser, G. (2010). "An agenda for research on the relationships between industrial design and performance." International Journal of Design, 4 (3) 67-77.

Candi, M., and Saemundsson, R. J. (20I I). "Exploring the Relationship Between Aesthetic Design as an Element of New Service Development and Performance."Journal of Product Innovation Management, 28(4), 536-557.

Coase, R. (1937). “The Nature of the Firm."Economica, 4, 386-405.

Dahlstrand, A. L., and Stevenson, L. (2010). "Innovative entrepreneurship policy: linking innovation and entrepreneurship in a European context."Annals of Innovation \& Entrepreneurship, I(I). I-I5

Daly, H. E. (1996). Beyond Growth. Boston: Beacon Press

Davis, E., and Kay, J. (1990). “Assessing corporate performance”. Business Strategy Review, I(2), I-I6.

de Chernatony, L., Harris, F., Riley, F. (2000) "Added value: Its Nature, Roles and Sustainability", European Journal of Marketing, 34(I/2), 39 - 56.

EPO \& OHIM (20I3). "Intellectual Property Rights Intensive Industries: Contribution to Economic Performance and Employment in The European Union”, Industry-Level Analysis Report. EPO \& OHIM: Münih

Er, H. A. ( 1997). "Development Patterns of IndustrialDesign in the Third World:A Conceptual Model for Newlylndustrialized Countries.”, Journal of Design History, 10(3), 293-307.

Europa Economics, (2015). The Economic Review Industrial Design in Europa, Europa Economics: London.

Flammang Robert A. (1979). "Economic Growth and Economic Development; Counterparts or Competitors?”Economic Development and Cultural Change, 28(I), 47-6I.

Fisher, A. G. (1939). "Production: Primary, Secondary and Tertiary."Economic Record, I5 (I) 24-38.

Greenhalgh, C. and Longland, M. (2002). "Running to Stand Still? - Intellectual Property and Value Added in Innovating Firms". Uwe Cantner (Ed.)9th Congress of the InternationalJoseph A Schumpeter Society. (ss. 30I-32I). Florida. 
Griliches, Z. (1995). R\&D and Productivity: Econometric Results and Measurement Issues. P. Stoneman (Editör). Handbook of the Economics of Innovation and Technical Change, Basil Blackwell, 52-89.

Grossman, G. and Helpman, E.(I99I). Innovation and Growth in the Global Economy, Cambridge: MIT Press.

Güneş, S., (20I I). “Design Integration and Organizational Routines”. ITU A|Z, 8(2), I22136.

Han, E. ve Kaya, A. A. (20I2). Kalkınma Ekonomisi: Teori ve Politika. Ankara: Nobel.

Haskel, J., Pesole, A. (20I I). Design services, design rights and design life lengths in the UK, Intellectual Property Office: Newport.

Hertenstein, J. H., Platt, M. B., and Veryzer, R. W. (2005). "The Impact of Industrial Design Effectiveness on Corporate Financial Performance."Journal of Product Innovation Management, 22(I), 3-2I.

Hoselitz, B. F. (1970). Ekonomik Kalkınmanın Sosyolojik Yönleri (çev. E. T. Çelikkan) Ankara: Yarın Yayınları.

Indecon, (2010). Economic Significance and Potential of the Crafts Sector in Ireland, The Crafts Council of Ireland: Kilkenny.

Kang, M. (2015). Industrial Design Policies: A Review of Selected Countries. OECD/OCDE: Paris.

Kuznets, S. (1955). "Economic Growth and Income Inequality”. American Economic Review, $45(I), I-28$.

Lucas, R. E. (1988). "On the Mechanics of Economic Development."Journal of Monetary Economics, 22 (I), 3-42.

Mutlu, B.D. ve Er, H. A. (2003). "Design Innovation:Historical and Theoretical Perspectives on Product Innovationby Design." David Durling (ed.)5th European Academy of Design Conference. Barcelona. Nelson, R.R. ve Winter, S.G. (1982). An Evolutionary Theory of Economic Change. Cambridge: Harvard University Press.

Porter, M. E. (1990). The Competitive Advantage of Nations. New York: Free Press.

Romer, P. M. (1990). “Endogenous Technological Change”. Journal of Political Economy, 98(5), $7 I-102$.

Rostow, W. W. (1960). The Stages of Economic Growth: A Non-Communist Manifesto. Cambridge: Cambridge University Press. 
Schumpeter, J.A. (1943). Capitalism, Socialism and Democracy. New York: Harper.

Solow, R. M. (1957). "Technical Change and the Aggregate Production Function."The Review of Economics and Statistics, 39(3), 3/2-320.

Sullivan, A. ve Sheffrin, S. M. (2003). Economics: Principles in Action. New Jersey: Pearson Prentice Hall.

The Danish Goverment, (2007). Design Denmark, : The Danish Goverment: Albertslund.

Williamson, O. E. (1975). Markets and Hierarchies: Analysis and Antitrust Implications. New York: Free Press.

Wallerstein, I. (1974). The Modern World System. New York: Academic Press. 
